\title{
SPATIAL DISTRIBUTION OF HYPOXIC WATER MASS BASED ON A MONITORINGCAMPAIGN OF BAY ENVIRONMENT AT TOKYO BAY, JAPAN.
}

\author{
Takehito HORIE ${ }^{1}$, Keita FURUKAWA² and Tomonari OKADA²
}

\begin{abstract}
In 2008, a monitoring campaign of bay environment had been done at Tokyo Bay, Japan. This campaign has been a part of implementation of the bay renaissance plan enacted since 2005. The data was collected by 46 institutions in 568 monitoring points in around 2nd July 2008. Dissolved oxygen, salinity and temperature were monitored in sea area basically from the surface to the bottom with $1.0 \mathrm{~m}$ vertical spacing at the monitoring points. We analyzed spatial distribution of hypoxic water mass based on this monitoring campaign data. Following results are obtained that 1) Measurement results showed that the bottom hypoxic water mass dominated in the head of Tokyo bay, while dissolved oxygen concentration was high condition in tidal flat and in shallow water, such as the Tama River estuary, Sanbanze tidal flat area and the Ara River estuary. 2) We proposed new parameters, such as CDz and VDZ, which showed characteristic of spatial distribution of hypoxic water. The proposed parameters could be related to the temporal and spatial development of hypoxic water. Thus, these parameters will extend the interpretation of conservative bottom dissolved oxygen (DОв) data to understand the dynamics of hypoxic water.
\end{abstract}

Keywords: Hypoxic water, Vertical profile of dissolved oxygen, Enclosed bay, Monitoring of coastal environment

\section{INTRODUCTION}

Hypoxic (dissolved oxygen concentration below $3.0 \mathrm{mgl}^{-1}$ ) and Anoxic (no oxygen) water in estuary are known to be one of the causes of the coastal environmental problems, and the dead zones have reported from more than 400 systems, affecting a total area of more than 245,000 $\mathrm{km}^{2}$ (Diaz and Rosenberg, 2008). The largest zone of oxygen depleted coastal waters in the United States is in the northern Gulf of Mexico on the Louisiana continental shelf, and the size of the Gulf of Mexico hypoxic zone reaches $20,000 \mathrm{~km}^{2}$ in mid-summer (Rabalais, 1999). Oxygen is necessary to sustain the life of most higher organisms, including the shellfish, the fish and invertebrate living in aquatic. One significant problem is the catastrophic mortality of benthic communities caused by coastal upwelling of hypoxic water. The point at which various animals are affected by low oxygen concentration varies, but generally effects start to appear when oxygen drops below 2 or $3 \mathrm{mgl}^{-1}$ (Diaz and Rosenberg, 2005). For example, hypoxic water exerts critical stress on larval survival, and may result in decline of juvenile recruitment to the benthic populations of short-necked clam in Tokyo bay (Toba et al., 2008).

It is important to understand dynamics (development and attenuation) of hypoxic water to assess the ecological effects on coastal ecosystems. One of well-used indices of the hypoxic water is bottomdissolved oxygen $\left(\mathrm{DO}_{\mathrm{B}}\right)$, which is a representative value of dissolved oxygen at bottom layer. However, it is difficult to reveal dynamics of hypoxic water from the $\mathrm{DO}_{\mathrm{B}}$ distribution only. In this paper, several parameters are defined to describe spatial and temporal dynamics of hypoxic water by using densely obtained vertical profile data of dissolved oxygen by a Tokyo-bay monitoring campaign in 2008. Incidentally, water with less than $3 \mathrm{mgl}^{-1}$ dissolved oxygen is considered hypoxic water mass in this paper.

\section{STUDY AREA}

Tokyo bay is situated in the central part of Japan (Figure 1) at lat. $35.5 \mathrm{degN}$ and long. 139.9degE and connects to the Pacific Ocean. Tokyo bay, one of the three major bays in Japan, is considered to be a typical enclosed bay. The bay has the shape of the letter ' $S$ '. Generally, the side to the north of broken line in Figure 1 is called 'the inner bay', and the opposite side calling 'outer bay'. In this paper, we call the inner bay simply Tokyo bay. The inner bay has a length of $50 \mathrm{~km}$ and a width of $20 \mathrm{~km}$. The average depth of inner bay is $15 \mathrm{~m}$, and its surface area is $960 \mathrm{~km}^{2}$ (Furukawa and Okada, 2005). Water depth in inner bay increases gradually from the head of the bay to the mouth of the bay. The maximum depth of the inner bay is about $50 \mathrm{~m}$ around broken line. The sea floor is covered by silt or sand. The currents in the bay are caused mainly by tides, density gradients, wind stress, and input of oceanic water. The catchment area of inner bay is $7548 \mathrm{~km}^{2}$. Rainwater falling in the catchment area of Tokyo Bay flows into the bay mainly through the Ara River, the Edo River and Tama River. These rivers discharge flow into the inner bay and the combined water discharge of these rivers accounts for approximately

\footnotetext{
${ }^{1}$ Alpha Hydraulic Engineering Consultants Co., Ltd., 2-7-9, Higashi Kanda, Chiyoda-ku, Tokyo, 101-0031, Japan

${ }^{2}$ National Institute for Land and Infrastructure Management, 3-1-1, Nagase, Yokosuka-shi, Kanagawa, 239-0826, Japan
} 
$50 \%$ of all fresh water entering the bay. The annual mean water discharge of the Edo River, the Ara River and the Tama River are about 76, 82 and $37 \mathrm{~m}^{3} \mathrm{~s}^{-1}$, respectively (Nihei et al., 2007).

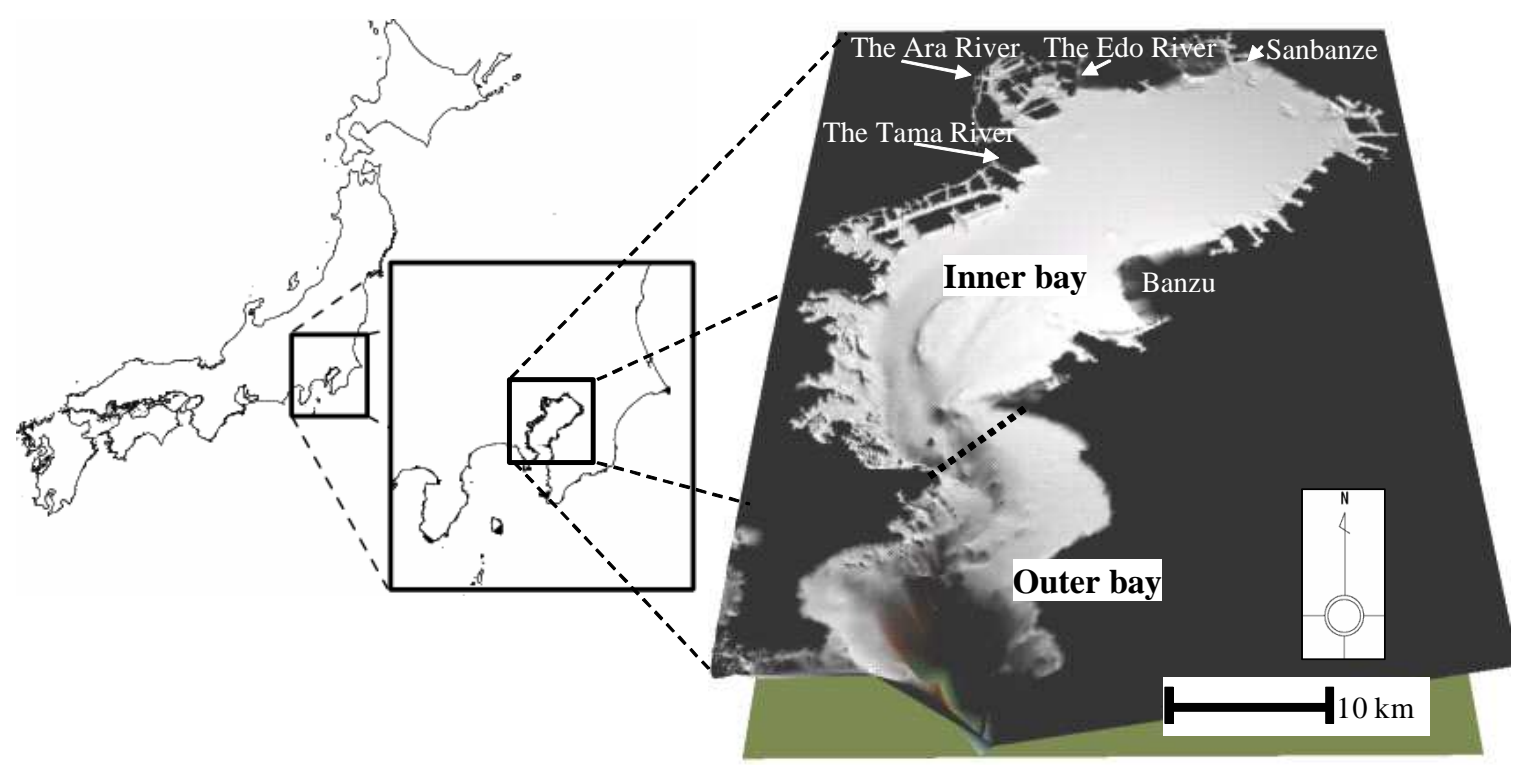

Figure 1. Location map of Tokyo bay

\section{WATER QUALITY IN TOKYO BAY}

In Tokyo bay, the nutrient load, such as Chemical Oxygen Demand (COD) reached its peak in the 1980's (Furukawa and Okada, 2005), but have decreased remarkably by conducting the marine environmental improvement project (1970's), the sea blue project to improvement (1980's) and the Eco-Port project (1990's). As a result, both the residence time of sea water and the nutrient load into the bay have decreased, yet the condition of eutrophication remains. The typical phenomena of eutrophication such as red tide, hypoxic and anoxic water and blue tide, which is called Aoshio or blue tide, still occur in Tokyo bay. Trend analysis of water quality using monitoring data obtained by Local Governments shows that the environmental status of dissolved oxygen has been worsening rather than improving (Figure 2, Ando et al., 2005).

In Tokyo Bay, large-scale red tides have repeatedly occurred from spring to early winter every year. The red tide condition is a phenomenon of phytoplankton bloom. The frequency of the red tide condition is about 100 days per year around Tokyo harbor. Blue tides, upwelling of anoxic waters, have occurred about 4 or 5 times per year in Tokyo bay. This phenomenon has been one of the most serious environmental problems issues in Tokyo Bay. The major sources of the blue tides are considered to be the anoxic waters containing hydrogen sulfide in dredged trenches, navigation channels and the flat bottom waters at the head of the bay (Sasaki et. all, 2007). In addition, the sulfide is harmful to marine organism. In Tokyo bay, strong stratification due to salinity gradient and temperature gradient occurs during summer. High oxygen consumption rate by bottom sediment accelerate oxygen depletion in inner bay. The frequency of the anoxic water condition in the bottom layer has almost remained constant at about 3 or 4 months per year since the 1980's.

In 2001, Cabinet Office, Government of Japan, declared to promote restoration of sea, and Tokyo Bay Renaissance committee was formed by local governments. The committee set a goal referring "Water Quality". Several working group was set to achieve this goal. Working group of Monitoring did the first attempt of integrated DO concentrate monitoring to clarify the mechanism of spatial distribution of hypoxia. This monitoring project was called a Monitoring Campaign of Bay Environment at Tokyo bay, and this was a challenge of Tokyo Bay Renaissance Committee for making a move of restoration (Horie et al., 2009). 


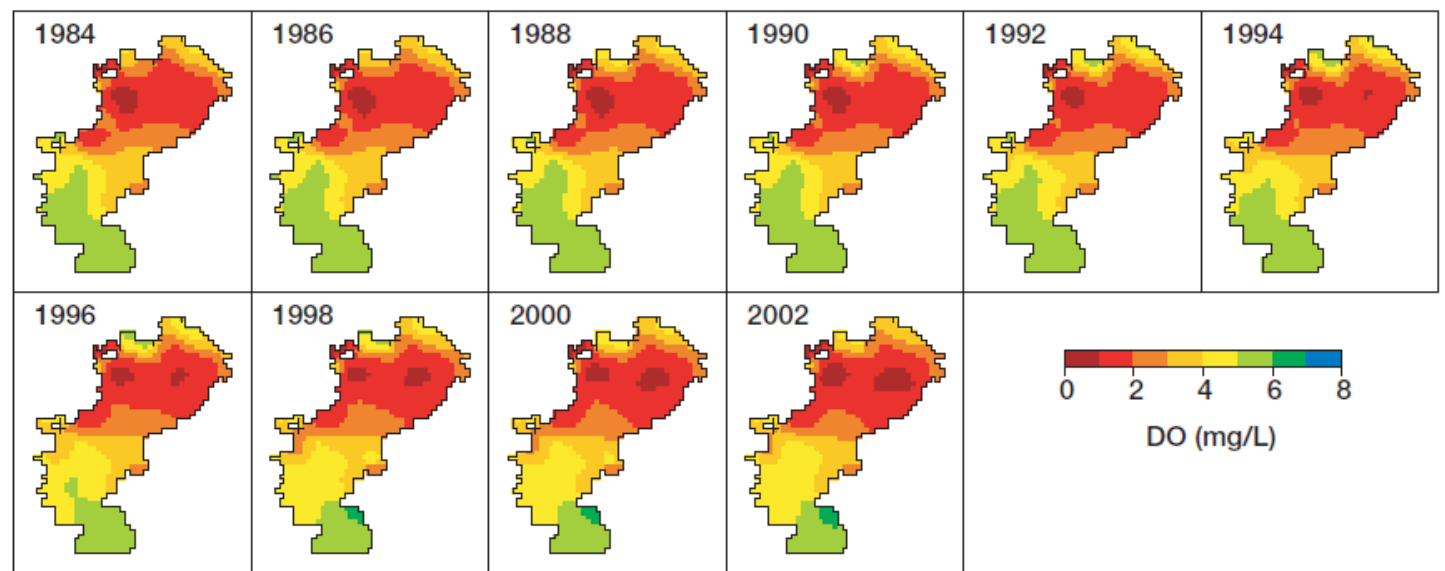

Figure 2. Long-term trends of distribution of bottom dissolved oxygen (DОв) on September in Tokyo bay (Ando et al., 2005)

\section{MONITORING CAMPAIGN OF BAY ENVIRONMENT}

A monitoring Campaign of Bay Environment was conducted on July 2th in 2008. This monitoring was the first attempt of integrated DO monitoring. Water qualities were simultaneously collected from more than 222 points on the sea and 281 points on inland water, as shown in Table 1 and Figure 3 . The nation, Local Gov., several universities, Citizen Groups for environment, company along the coast, elementary school, and laboratory staff participated in this monitoring campaign. Figure 3 shows location of observation points at this monitoring. Dissolved oxygen, Temperature and Salinity were measured from surface to bottom with vertical spacing of $1.0 \mathrm{~m}$ at the monitoring points in sea area. Chemical-oxygen-demand (COD), Temperature and water discharge were measured in river area. The water discharge was measured at approximately $20 \%$ of the depth below the water surface, and the others measuring at the water surface.

\begin{tabular}{|c|c|}
\hline \multicolumn{2}{|c|}{ Table 1. A Monitoring Campaign of Bay Environment at Tokyo Bay (July 2, 2008) } \\
\hline Observation day & July 2, 2008 \\
\hline Observation point & $\begin{array}{l}\text {-Total survey points:568 points } \\
\text {-Sea area:222 points } \\
\text { - River:281 points } \\
\text { - Lake:1 point } \\
\text { - Sewage disposal plant:64 points }\end{array}$ \\
\hline $\begin{array}{l}\text { Participating } \\
\text { Organization }\end{array}$ & $\begin{array}{l}\text {-Total } 46 \text { organizations } \\
\text {-Governments } \\
\text { - MLIT, ME and MTSA } \\
\text { - Local Gov. (19 sectors) } \\
\text { - Fisheries (CHIBA, KANAGAWA) } \\
\text { - Institutes (TOKYO, NIES, PARI) } \\
\text { - Univ. (TOKYO, TITECH, TUMS,TOHO) } \\
\text { - Privates (TGn, TGs, JFE, DK, KTC) } \\
\text { - NPOs (FTKJ, EE) } \\
\text { - Schools (KWPS) }\end{array}$ \\
\hline Observation items & $\begin{array}{l}\text { 【Sea area】 } \\
\text { Dissolved oxygen concentration (DO), Temperature and Salinity } \\
\text {-They were measured from surface to bottom with vertical spacing of } 1.0 \mathrm{~m} \text { at the } \\
\text { monitoring points. } \\
\text { 【River area】 } \\
\text { Chemical-oxygen-demand (COD), Temperature and River discharge } \\
\text {-The discharge was measured at approximately } 20 \% \text { of the depth below the water } \\
\text { surface, and the others measuring at the water surface. }\end{array}$ \\
\hline
\end{tabular}




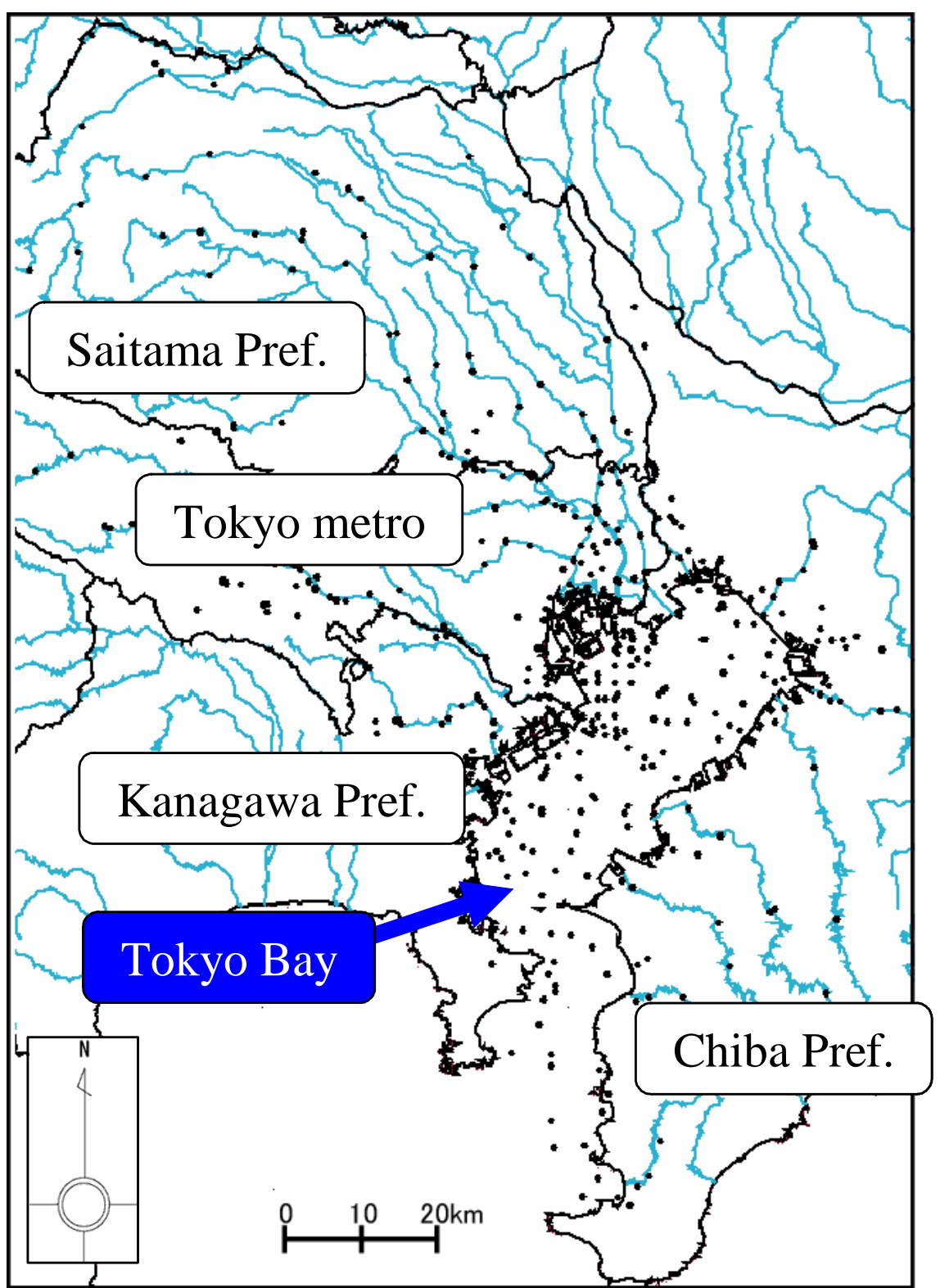

Figure 3. Location of observation points at the Monitoring Campaign of Bay Environment on July 2th in 2008.

\section{Natural Condition}

Figure 4 shows the time series of (a) wind velocity vector at Tokyo light Beacon, (b) tidal wave at Shibaura tidal station, (c) the mean daily precipitation at each weather offices, and (d) DO concentration profile at Chiba light beacon for 21 June to 6 July. Each observation point is identified in Figure 5. Chiba light beacon has been conducted continuously measurement of dissolved oxygen, salinity and temperature with vertical spacing of $1.0 \mathrm{~m}$.

The south wind was blowing the day before and the day after the monitoring day. A high south wind over $15 \mathrm{~ms}^{-1}$ was recorded on the day of monitoring. It hadn't rained for 3 days around Tokyo-bay prior to the day of monitoring. The low oxygen water mass on the bottom water at Chiba light beacon changed the configuration in response to south wind. During the observation day, hypoxic water at Chiba light beacon appeared to be kept decreasing. This reason is that the low oxygen water mass on the bottom water moved to west in response to south wind (Yagi et al., 2008b). Continuous bottom water dissolved oxygen data for Chiba light beacon indicated fluctuations between 0 and $3 \mathrm{mgl}^{-1}$ from June 23 to July 3. 
(a) Wind speed and wind direction(Tokyo light beacon)

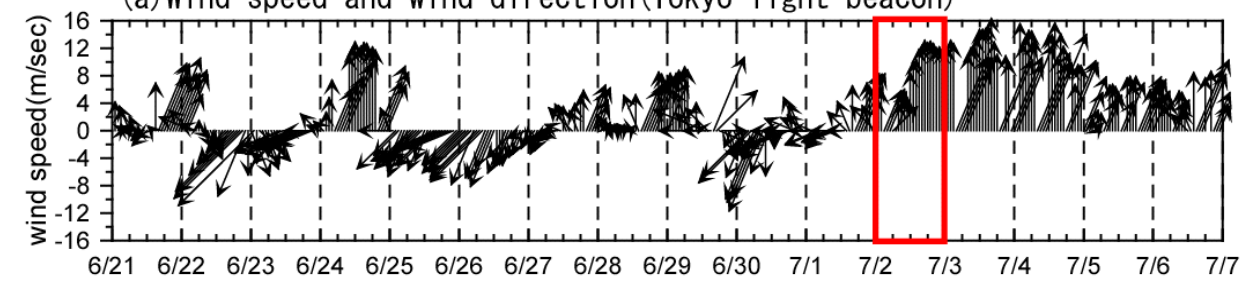

(b) Tidal wave (Shibaura)

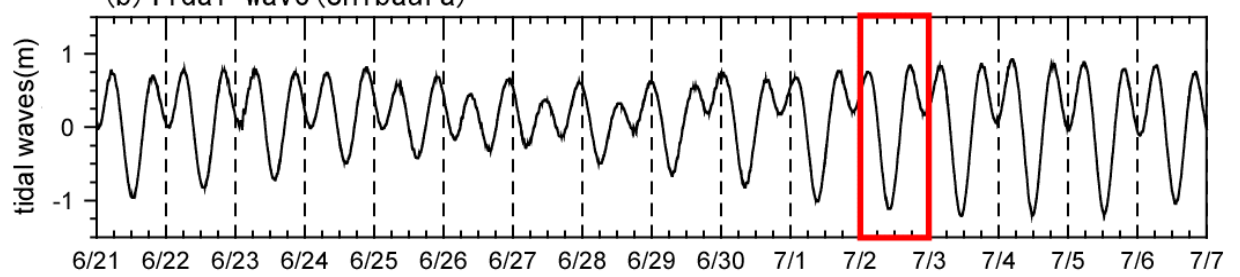

(c) Precipitation (Tokyo, Yokohama and Chiba)

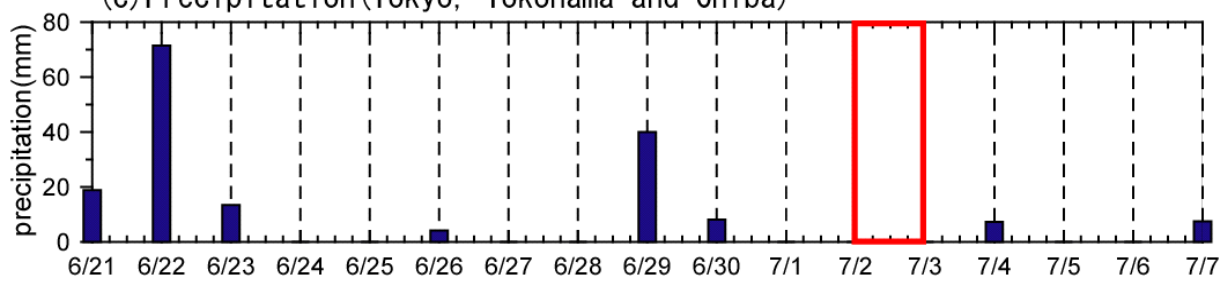

(d) D0 concentration (Chiba I ight beacon)

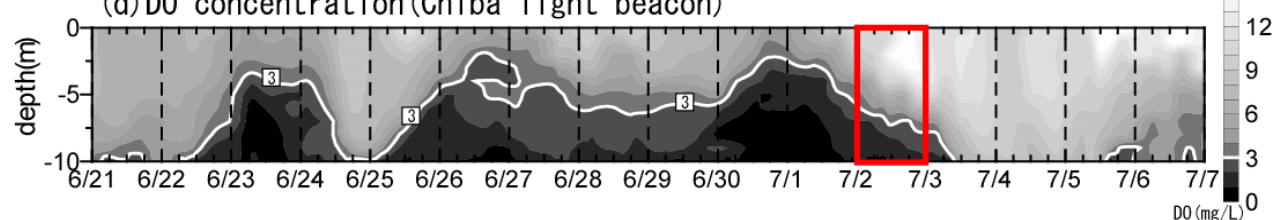

Figure 4. Time series of (a) wind velocity vector at Tokyo light beacon, (b) tidal wave at Shibaura tidal station, (c) the mean daily precipitation at each weather offices, and (d) DO concentration profile at Chiba Light Beacon Monitoring Post for 21 June to 6 July. Each observation point is identified in Figure 5.

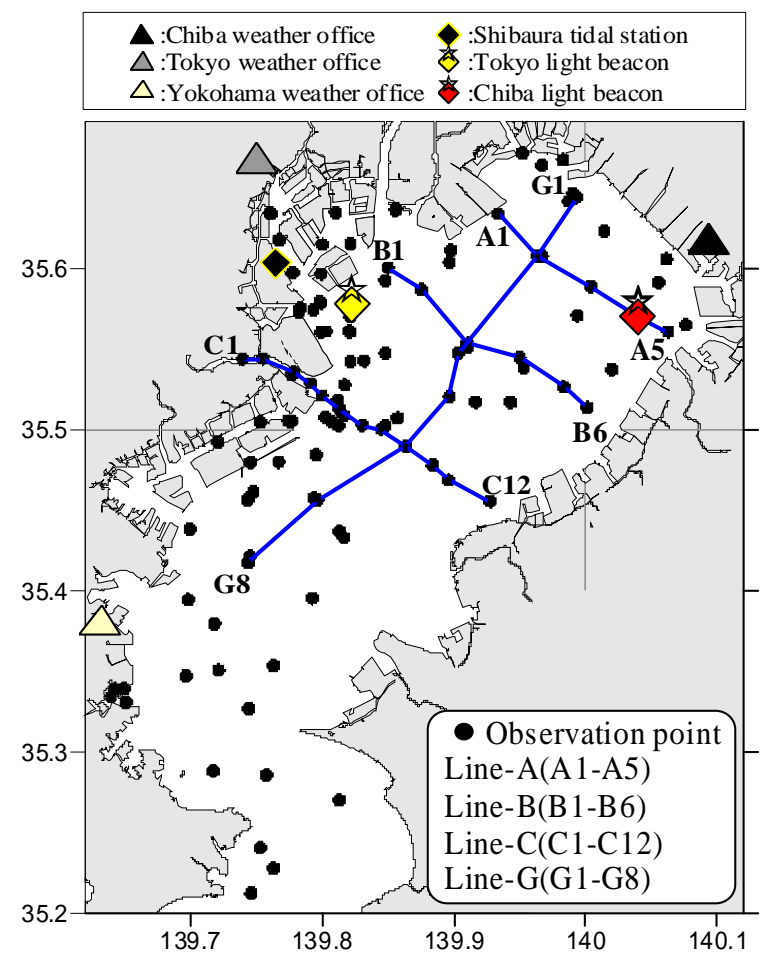

Figure 5. Location of observation points (Tokyo light beacon, Shibaura tidal station, weather offices, Chiba light beacon Monitoring Post), and profile-lines in the Monitoring Campaign of Bay Environment on July 2th in 2008. 


\section{INNER BAY CHARACTERISTIC}

Figure 6 shows DO concentration profiles and density profiles at Line-A, B, C and G on July 2th in 2008. Each Line is identified in Figure 5. Density was calculated by an adaptation of the UNESCO equation of state devised by Mellor (1991). Depending on the depth of the water and the location of the pycnoclines, hypoxia occurred not only at the bottom near the sediments, but well up into the water column at Line-A, B, C and G. The location of the pycnoclines was same as the location of $3.0 \mathrm{mg}^{-1}$ dissolved oxygen concentration at Line-A, and Line-B. Pycnoclines inclined to the east coast at Line-A, $\mathrm{B}, \mathrm{C}$, and $3.0 \mathrm{mg}^{-1}$ dissolved oxygen concentration also inclined to the east coast at Line-A, B, C. Strong south wind forced the oceanic water to return to the bay mouth and induced the coastal upwelling to occur at the west coast of the bay (Yagi et al., 2008b). Thus, hypoxic water mass could be moving from $\mathrm{C} 12$ (the east coast of the bay) to $\mathrm{C} 1$ (the west coast of the bay) during this Monitoring Campaign of Bay Environment.
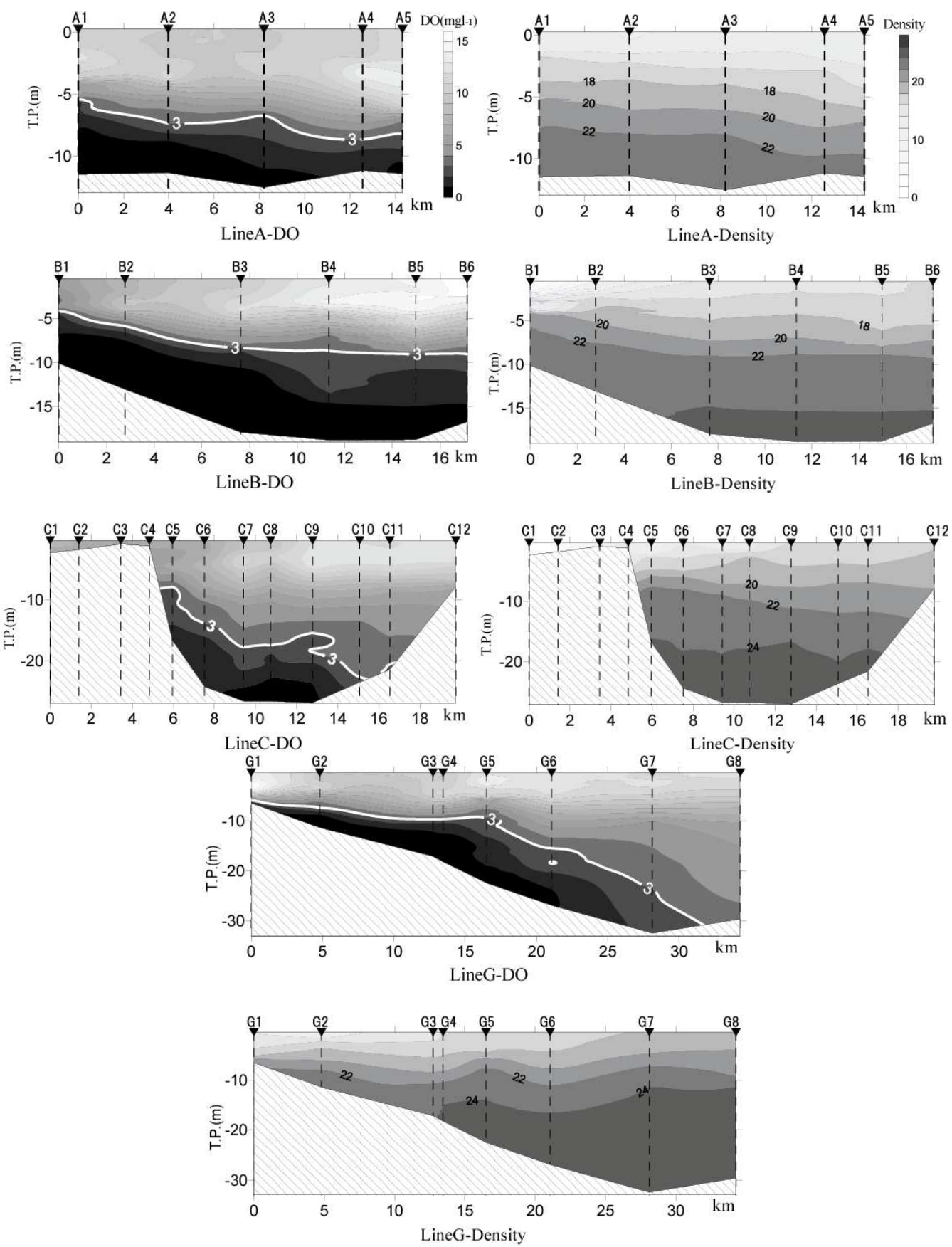

Figure 6. DO concentration profiles and Density profiles at Line-A, B, C and G on July 2th in 2008. Each Line is identified in Figure 5. 


\section{BOTTOM DISSOLVED OXYGEN (DОв)}

Figure 7 shows distribution of DОв $\mathrm{mg}^{-1}$. DОв is short for "bottom dissolved oxygen". Нypoxic water was distributed along the coastline excluding tidal flats and shallows in the bay head, such as the Tama River estuary, Sanbanze tidal flat area and the Ara River estuary. Anoxic water was distributed particularly at the deeper part of the head. The values of DOв were almost the same at A, B, C, and D in Figure 7, that is, we can't understand the difference of the strength of hypoxia or dynamics of hypoxia among the locations. One of well-used indices of the hypoxic water is DОв, which is a representative value of dissolved oxygen at bottom layer. However, it is difficult to reveal dynamics of hypoxic water from the DОв distribution only. For example, we can see that hypoxic water mass occurred not only at the bottom near the sediment, but also well up into the water column in Figure 6. The difference of distribution of DO in hypoxic column would be determined mainly by oxygen consumption rate and advection current of bottom water mass, that is, we need to introduce several parameters to describe spatial and temporal dynamics of hypoxic water by using densely obtained vertical profile data of dissolved oxygen.

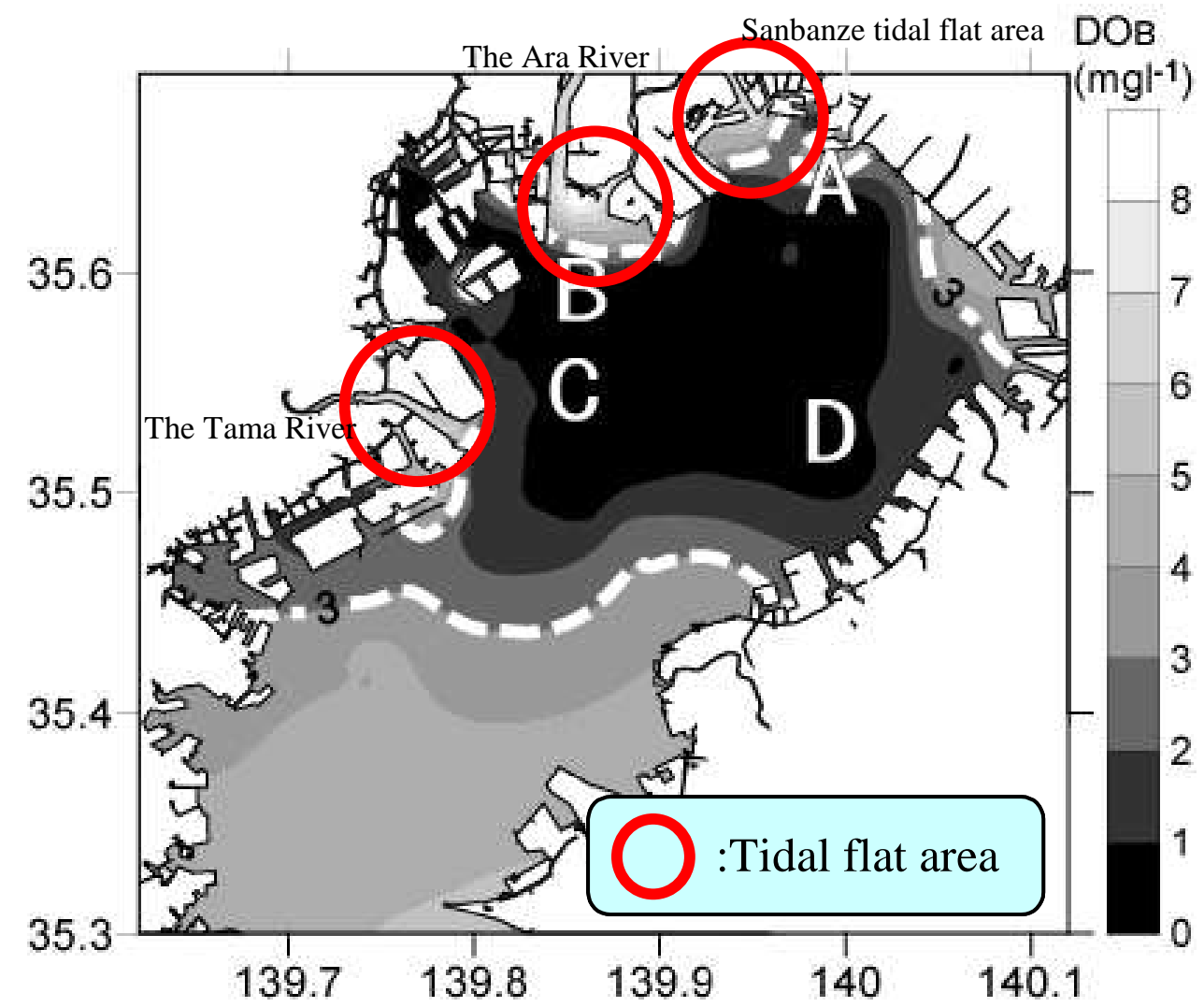

Figure 7. Distribution of Bottom dissolved oxygen (DОв) and the location of tidal flat area on July 2th in 2008.

\section{PARAMETER OF HYPOXIC WATER, CDz}

We define parameters, which are $\mathrm{CDZ}\left(\mathrm{mgl}^{-1}\right)$ and $\operatorname{VDz}\left(\mathrm{gm}^{-2}\right)$, to be able to compress complicated variability of spatial distribution of hypoxia into a simple expression.

Firstly, we proposed $\mathrm{CDz}\left(0 \leq \mathrm{C}_{\mathrm{DZ}}\left(\mathrm{mgl}^{-1}\right) \leq 3.0\right)$. CDz is defined as shown in Equation (1). Here, ZDZ (m) is the thickness from sea bottom to the depth of $3.0 \mathrm{mg}^{-1}$ dissolved oxygen concentration, C $\left(\mathrm{mg}^{-1}\right)$ is the dissolved oxygen concentration and $\mathrm{h}(\mathrm{m})$ is the height from sea bottom (Figure 8). Parameter CDZ indicates the "strength" of hypoxia. If CDZ equals zero, the water mass below ZDZ is anoxic water. Figure 9 shows distribution of parameters of hypoxic water, CDZ. As shown from Figure 9 , the value of $\mathrm{CDZ}$ at $\mathrm{B}$ was smaller than that at $\mathrm{D}$. The water height of $\mathrm{B}$ equaled to one of $\mathrm{D}$. As mentioned above, it is thought that hypoxic water mass could be moving from D to B (Figure 6). This time, the reason that the value of $\mathrm{CDZ}$ at $\mathrm{B}$ was smaller than that at $\mathrm{D}$ is thought that hypoxic water mass could be moving from $\mathrm{D}$ to $\mathrm{B}$. 


$$
C_{D Z}=\frac{1}{Z_{D Z}} \int_{0}^{Z_{D Z}} C(h) d z
$$

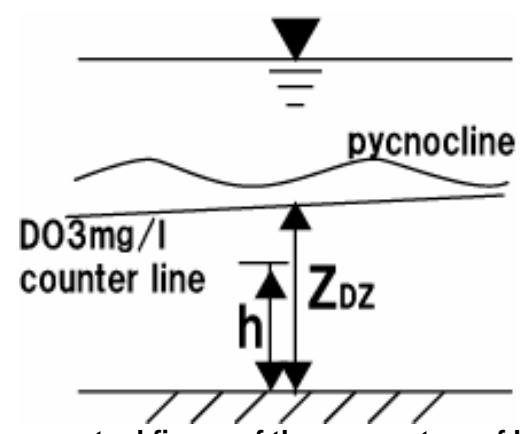

Figure 8. A conceptual figure of the parameters of hypoxic water

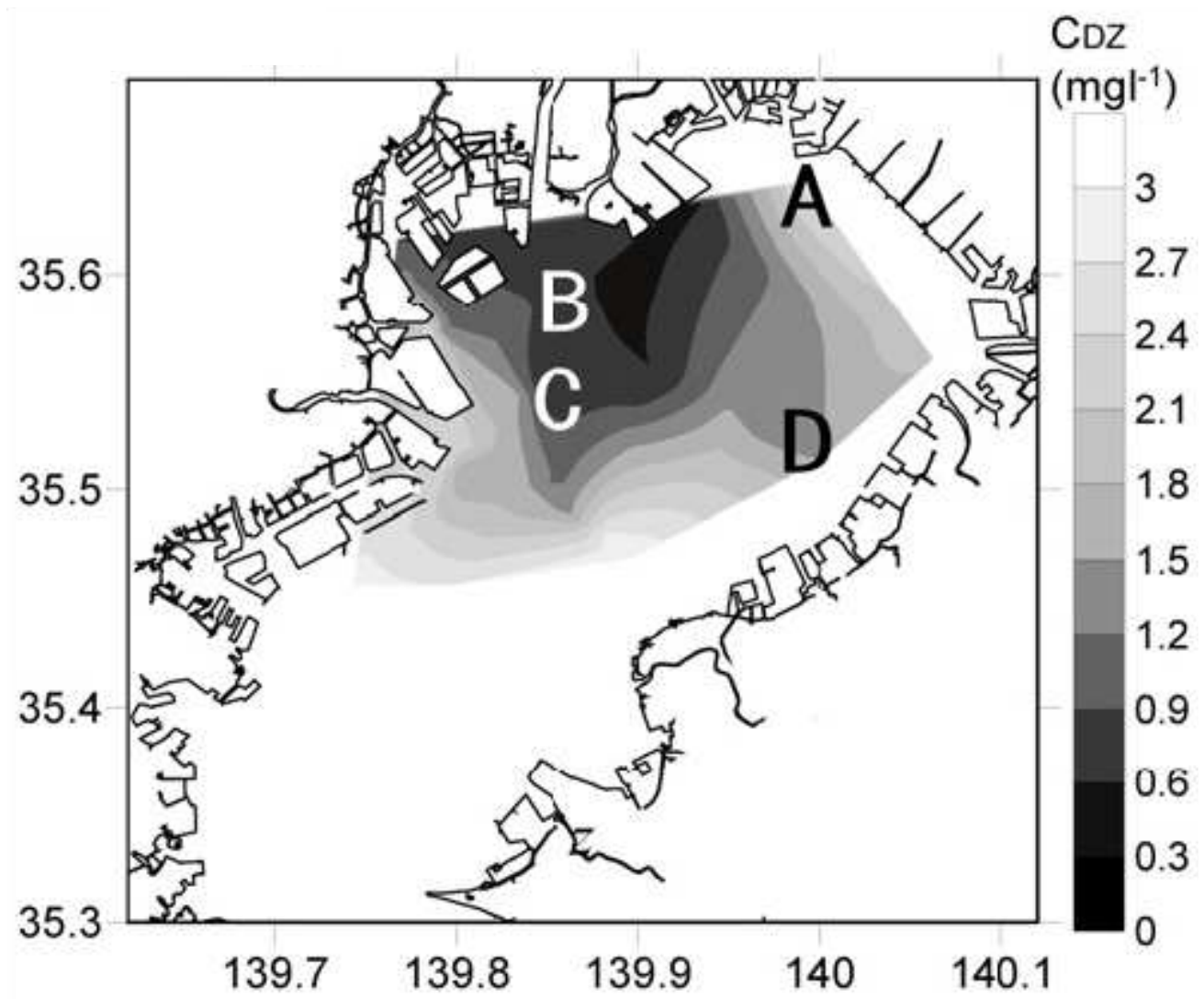

Figure 9. Distribution of parameters of hypoxic water, Coz, on July 2nd, 2008

\section{PARAMETER OF HYPOXIC WATER, VDZ}

Next, we proposed VDZ. VDZ is defined as shown in Equation (2). Here, the value of 3.0 in Equation (2) shows threshold value of dissolved oxygen of hypoxic water mass. VDZ has thickness of hypoxia "ZDz" and the strength of hypoxia "CDZ". That is, this parameter VDz indicates quantity of depleted oxygen by oxygen consumption and/or advection current of bottom water mass. Figure 10 shows distribution of VDZ. The value of VDZ was highest at C. That is to say, hypoxia around C area could be the most development in all observation point at the monitoring day. That is, quantity of dissolved oxygen at $\mathrm{C}$ is the smallest in inner bay.

In inner bay, when heavy saline water intruded into the lower layer from off the bay mouth, the subsurface oxygen appears frequently (Fujiwara et al., 2000 and Yagi et al., 2008a). It is difficult to calculate the parameters, CDZ and VDZ, under the condition of subsurface hypoxic water. 


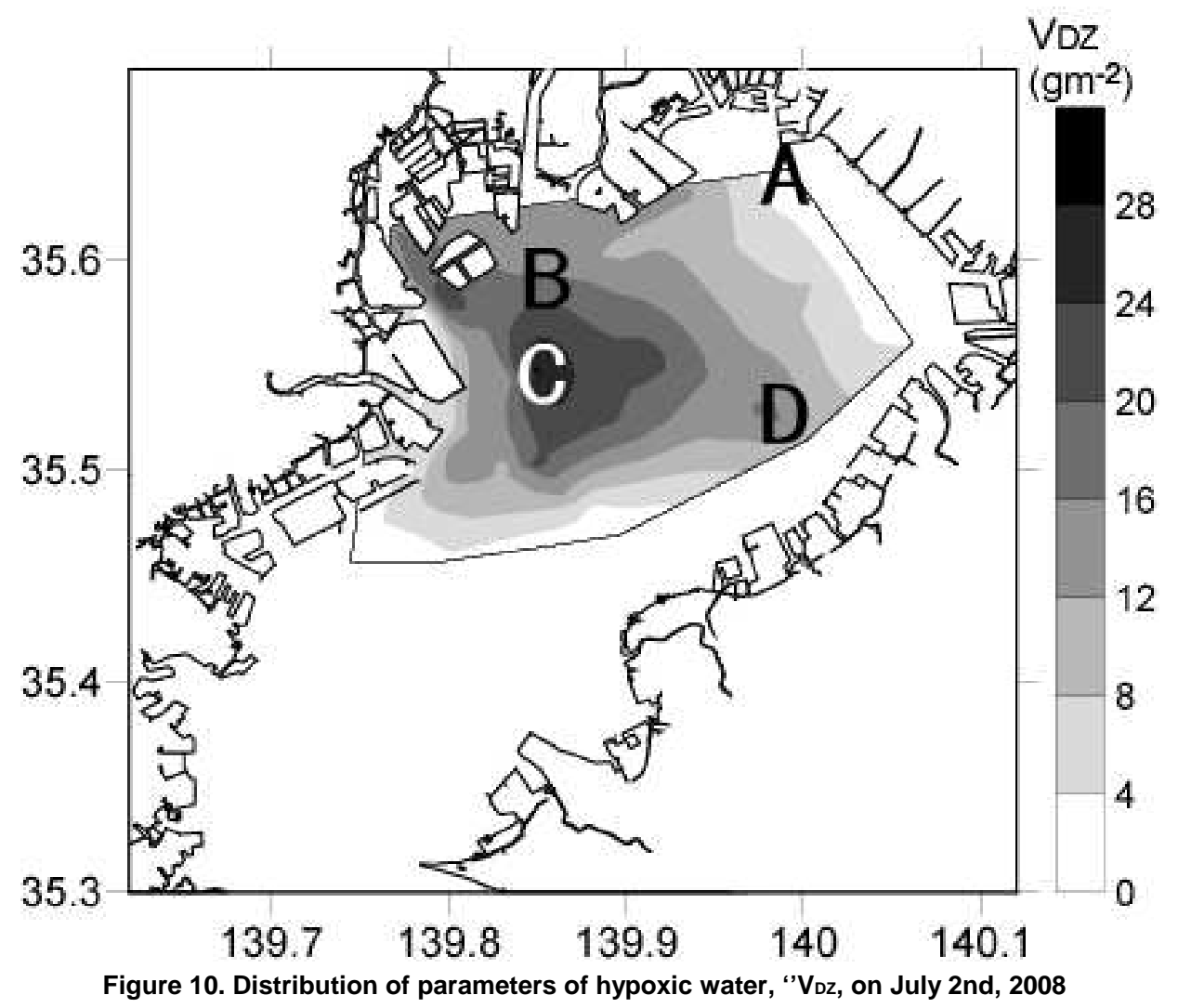

$$
V_{D Z}=Z_{D Z}\left(3.0-C_{D Z}\right)
$$

\section{CONCLUSION AND FUTURE STUDY}

A monitoring Campaign of Bay Environment was conducted to clarify the mechanism of spatial distribution of hypoxia on July 2 in 2008. The bottom hypoxic water mass dominated in inner bay area on this monitoring day, while dissolved oxygen concentration was high condition in tidal flat and in shallow water. One of well-used indices of the hypoxic water is DОв, which is a representative value of dissolved oxygen at bottom layer. However, it is difficult to reveal dynamics of hypoxic water from the DOв distribution only. So, several parameters, which are CDZ and VDZ, are defined to describe spatial and temporal dynamics of hypoxic water. The proposed parameters could be related to the temporal and spatial development of hypoxic water. These parameters will extend the interpretation of conservative DOв data to understand the dynamics of hypoxic water. In order to get the parameters, such as CDZ and VDZ, it is important to observe not only bottom dissolved oxygen (DОв) but also vertical profile data of dissolved oxygen, that is, it is important for us to keep conducting a Monitoring Campaign of Bay Environment at Tokyo Bay in the future. In 2010, a monitoring campaign of bay environment was conducted not only in Tokyo Bay but also in Osaka bay, Ise bay and Hiroshima bay.

\section{REFERENCES}

Ando, H., Kashiwagi, N., Ninomiya, K., Ogura, H. and Kawai, T. (2005): Changes in the State of Water Pollution in Tokyo Bay since 1980 -Trend analysis of water quality using monitoring data obtained by Local Governments -, Annual report of the Tokyo Metropolitan Research Institute for Environmental Protection 2005, pp.141-150. (in Japanese)

Diaz, R.J. and Rosenberg, R. (2008): Spreading Dead Zones and Consequences for Marine Ecosystems, Science 321, 926, 2.

Diaz, R.J. and Rosenberg, R. (2005): A review of its ecological effects and the behavioural responses of benthic macrofauna, Oceanogr. Mar. Biol. Ann. Rev., 33, pp.245-303. 
Furukawa, K. and Okada, T. (2006): Tokyo Bay: Its Environmental Status-Past, Present, and Future, The Environment in Asia Pacific Harbors, 2006 Springer, pp.15-34.

Fujiwara, T., Takahashi, T., Yamada, Y. and Kaneko, A. (2000): Response of Hypoxic Water Mass in Tokyo Bay to the Variation in Hydrographic Condition Outside of the Bay, Oceanography in Japan, 9(6), pp.303-313. (in Japanese)

Horie, T., Furukawa, K. and Okada, T. (2009): Spatial Distribution of Hypoxic Water Mass Based on a Monitoring Campaign of Bay Environment at Tokyo Bay, Japan., Annual Journal of Civil Engineering in the Ocean, JSCE, Vol.26, pp.567-572. (in Japanese)

Mellor, G. L., (1991): An equation of state for numerical models of oceans and estuaries, J. Atmos. Oceanic Technol., 8, pp.609-611.

Nihei, Y., Takamura, T. and Watanabe, N. (2007): Issues on Discharge Monitoring in Main Influent Rivers into Tokyo Bay, Annual Journal of Coastal Engineering, JSCE, Vol.54, pp.1221-1225. (in Japanese)

Rabalais, N. N. (1999): Press release dated July 29, 1999, Louisiana Universities Marine Consortium, Chauvin, Louisiana.

Sasaki, J., Kawamoto, S., Yoshimoto, Y., Ishii, M. and Kakino, J. (2007): Evaluation of the Effect of Anoxic Water in Dredged Trenches on Blue Tides in Tokyo Bay, Annual Journal of Coastal Engineering, JSCE, Vol.54, pp.1041-1045. (in Japanese)

Toba, M., Kosemura, T., Yamakawa, H., Sugiura, Y. and Kobayashi, Y. (2008): Field and laboratory observations on the hypoxic impact on survival and distribution of short-necked clam Ruditapes philippinarum larvae in Tokyo Bay, central Japan., Plankton and Benthos Research, Vol.3, No.3, pp.165-173.

Yagi, H., Pokavanich, T., Susumu, Y., Nadaoka, K., Ariji, R., Matsuzaka, S., Suzuki, N., Moroboshi, K., Oda, R. and Ninei, Y. (2008a): Temporal and spatial variations of hypoxic water mass in Tokyo bay governed by the coastal upwelling at bay mouth and wind-driven current, Annual Journal of Coastal Engineering, JSCE, Vol.55, pp.1081-1085. (in Japanese)

Yagi, H., Pokavanich, T., Ise, H., Nadaoka, K., Ariji, R., Furudoi, K., Geshi, H., Furudono, T., Y. Oono (2008b): Influence of oceanic water intrusion on the coastal environment off Tama River Estuary of Tokyo bay in winter, Annual Journal of Coastal Engineering, JSCE, Vol.55, pp.10861090. (in Japanese) 